\title{
Air \& Noise control and Analysis in Construction Industry
}

\author{
P. Bishnoi ${ }^{1}$ \\ ${ }^{1}$ Civil Environmental Engineering, \\ Babu Banarasi Das University, Lucknow- 226028 (U.P), \\ India,
}

\author{
Kamal Nabh Tripathi ${ }^{2}$ \\ ${ }^{2}$ Assistant Professor, \\ Civil Engineering Department, \\ Babu Banarasi Das University, Lucknow- 226028
}

(U.P),India.

\begin{abstract}
Major environmental issues related to ongoing construction industry like air emission and Noise pollution have been arrised and impacted on the construction workers and also surroundings. Particulates (dust) are generated from various activities of construction sites excavation, drilling, bulk material transportation, loading and unloading; open-air material storage, concrete and mortar making; cut and fill operations; and movement of equipment and but not limited to. These major activities have significant impacts of existing environment. Dust pollution can cause numerous health issues among construction workers and many studies have dealt with this problem. In addition, safety, comfort and the morale of workers is affected by dust pollution. Dust also creates problems with the neighborhood and is considered to be a nuisance [3]. Many construction procedures, such as drilling and grinding, can produce high level of particulates that can be inhaled into lung, and consequently lead to physical diseases $[4,5]$.
\end{abstract}

Considering the above situation the present work focuses on the monitoring of the different sources of Particulate matter \& Noise generation in different areas using the samplers. Ambient air monitoring was conducted from March 2017 to February 2018 at an averaging period of 24 hour and monthly basis to derive the particulate matter generation behaviour in and around the sites. Seasonal variation on ambient air quality data have been noticed quite markedly. It is found that the monitored particulate matter concentrations thus obtained were not within the prescribed limits of NAAQS 2009. On the basis of these findings suitable mitigation and environmental plans can be devised for the sensitive areas. Ambient Noise have also been affected, the results were analyzed \& compared with baseline survey.

Keywords: Particulate Matter (PM), National Ambient Air Quality (NAAQ), Central pollution control board (CPCB)

\section{INTRODUCTION}

\subsection{GENERAL:}

Now a days, Government has taken steps to improve public transportation system in order to avoid increased traffic demand, vehicles increase on the road, traffic congestion, road accidents and significant environmental pollution. Metro transport system have been introduced in many developing cities like Kolkata, Delhi, Mumbai, Chennai etc and are also being provided in other cities in India. Athough

\author{
Anupam Malhotra ${ }^{3}$ \\ ${ }^{3}$ Head of the Department, \\ Civil Engineering Department, \\ Babu Banarasi Das University, Lucknow- 226028 (U.P), \\ India
}

this system contributes substantially the reduction of air and noise pollution through the decrease in the number of cars and heavy vehicles circulating in the road network, the works related its construction may pose an extra burden in air and noise quality status and advance impact on public health.

Regarding the rapid development of cities, underground constructions at urban regions such as metro construction have been largely used for extending the human daily life into underground spaces. Metro rail systems are known as convenient underground transportation solutions amongst citizens [2]. Major environmental issues related to ongoing construction industry like air emission and Noise pollution have been arrised and impacted on the construction workers and also surroundings.

Particulates (dust) are generated from various activities of construction sites excavation, drilling, bulk material transportation, loading and unloading; open-air material storage, concrete and mortar making; cut and fill operations; and movement of equipment and but not limited to. These major activities have significant impacts of existing environment. Dust pollution can cause numerous health issues among construction workers and many studies have dealt with this problem. In addition, safety, comfort and the morale of workers is affected by dust pollution. Dust also creates problems with the neighborhood and is considered to be a nuisance [3]. Many construction procedures, such as drilling and grinding, can produce high level of particulates that can be inhaled into lung, and consequently lead to physical diseases $[4,5]$.

Negative effects of particulate and gaseous construction site emissions on the health of construction workers [6,7] as well as on public health can therefore not be excluded [8]. Characteristics of the particulate and gaseous emissions depends on the construction specific activities, machines and tools used.

Particulate matter is one of the major threat to environment once it becomes airborne. These airborne 
particulate matters leads to several severe health problems such as, visible impairment, Pneumoconiosis, allergic reactions etc. Dusts, as per the size of particulates are classified mainly as total suspended particulates (TSP), Particulate matter of size less than 10 microns (PM10) and Particulate matter of size less than 2.5 microns (PM2.5). These particulate matters are basically measured in microgram per cubic meters. It is necessary to identify the emission sources of different construction activities so that there impacts on the surrounding air quality can be known and depending on its severity proper preventive measures could be devised. It is equally important to know the constituents of these particulate matters in order to find the correct pollutant composition and types of health issues it can create on miners and the people residing in the nearby areas.

Noise is generally considered to be undesirable sound and sound can be considered undesirable due to amplitude or volume of loudness, category of noise, about the day, or any modality making resonance or obscene. Construction noise contributors include pneumatic equipments, air compressors, machine mounted percussion drills, loaders, trucks and breaking equipments.

\section{LITERATURE SURVEY}

Lucknow city is the capital of Uttar Pradesh which has a population of 2.82 millions (Municipal Corporation and Cantonment). Lucknow is already being experienced with severe air pollution issues for past few years due to vehicular emissions and day by day increasing private vehicles on road, rapid urbanization on the expenditure of greenery and industries surrounding the city.

According to a study of 17 cities covered by the National Air Quality Index (NAQI) and released by Greenpeace India on 15th Dec 2015, Lucknow is among the six most highly polluted cities in India. The level of Particular Matter (PM2.5) in the air should be 60 micrograms per cubic metre for the 24 hour standard whereas in Lucknow it was found to be 411 micrograms per cubic metre on an average. Moreover, when the data for this year was compared with the previous years, it showed an increasing trend of air pollution. Central Pollution Control Board officials stated that a high level of Particular Matter in the air particularly, is of grave concern for the health of the people as well as the environment of Lucknow City.

Despite being an sustainable means of public transportation, Metro rail construction works may often add into local air pollution in commercial and residential areas specially particulate and gaseous pollution in ambient air.

Noise is one of the most important acoustic pollutants in the nowadays society, as it is present in most of people's activities, consequently, not only the workers of certain sectors, but all the citizens, are exposed to high noise doses. Hence, a set of political actions regarding that topic has been developed with the aim of decreasing the noise pollution in our environment, creating then, more sustainable cities. These policies point out to the control of traffic noise (by road, train or airplanes), and therefore, laws have been set to establish the methods for assessing and controlling the noise. Nevertheless, there are other types of sources that emit high levels of noise and have intrinsic characteristics that make them different from the former and then, they cannot be regulated by the same rules. Among these sources, the activities produced in a construction set are very present in the urban environment and they increase the noise pollution temporarily [10].

Government laws are in place and plays a vital role to ensure that construction industry is working safely, not polluting the environment. In India, Central pollution control board is responsible to implement relevant dust regulations and noise prevention policies for the construction industry. Not limited to government guidelines, Industry also have their own policies to control the air and pollution effects for the workers and staffs.

Guidelines for dust mitigation measures are prescribed by Central pollution control Board. Different C \& D operations e.g dust from loading / unloading operations, due to vehicle movement, due to machinery used [11].

National Ambient Air Quality Standards - includes PM10 and PM2.5 The basis of development of standards is to provide a rational for protecting public health from adverse effects of air pollutants, to eliminate or reduce exposure to hazardous air pollutants, and to guide national/local authorities for pollution control decisions. CPCB revised and notified in year 2009 the National Ambient Air Quality Standards (NAAQS) (http://www.cpcb.nic.in) for 12 parameters viz. carbon monoxide (CO) nitrogen dioxide (NO2), sulphur dioxide (SO2), particulate matter (PM) of less than 2.5 microns size (PM2.5), PM of less than 10 microns size (PM10), Ozone (O3), Lead (Pb), Ammonia (NH3), Benzo(a)Pyrene (BaP), Benzene (C6H6), Arsenic (As), and Nickel.The first eight parameters include PM (PM10 and PM2.5), have short-term (1/8/24 hours) and annual standards (except for $\mathrm{CO}$ and $\mathrm{O} 3$ ) and rest four parameters have only annual standards [12].

The main sources of noise at a construction site include construction machines (mainly machines which produce impacts, e.g. devices for breaking concrete), earth-moving machines, pile drivers, pneumatically driven devices and combustion engines. For the purposes of noise studies, these mechanisms must be considered to be point or linear noise sources depending on the level of movement at the construction site. Some types of construction projects are not endangered by increased noise pollution at all, while others are, but only when particular conditions coincide. In the case of certain construction sites, increased impact can already be expected from the very nature and location of the project [13].

Government prescribed and set ambient noise levels generated from construction activity to prevent deleterious effects on human health and the psychological well being of the people; it is considered necessary to regulate and control noise producing and generating sources with the objective of maintaining the ambient air quality standards in respect of noise [14]. 


\section{PROBLEM DEFINITION}

The particulate matter which proves to be the main source of air pollution in construction areas needed to be assessed. Among various pollutions noise pollution is one of the major contributions of construction industry. This current work has been planned with the following objectives:

(a) Collection of the Ambient Air Quality data monitoring data of Lucknow metro construction locations \& Comparison with Baseline survey. For the ambient air quality objective, it is necessary to determine the concentration of the substance at the ground level.

(b) To study the impact of noise pollution at construction site.

\section{METHODOLOGY}

\subsection{PM10 Sampling:}

In the present work the PM10 sampling is performed by Respirable dust Sampler Principle: Air is drawn through a size-selective inlet and through a $20.3 \mathrm{~cm} \times 25.4 \mathrm{~cm}$ filter at a flow rate of about 1132 liter per minute. The particles with aerodynamic diameter less than the cut-point of the inlet are collected by the glass fiber filter paper. The concentration can be determined by the difference in filter weights prior to and after sampling. Concentration of PM10 in the designated size range is calculated by dividing the weight gain of the filter by the volume of air sampled by it.

\subsection{PM2.5 Sampling:}

Sampler draws the ambient air at the constant volumetric flow rate of $16.71 \mathrm{pm}$ through the cyclones/impactors. Here the suspended particulate matter of aerodynamic diameter less than 2.5 microns are separated and is collected on a $47 \mathrm{~mm}$ PTFE (polytetrafluoroethylene) filter. The filter is weighed before and after the sampling, the difference gives the amount of particulate matter concentration (PM2.5) in $\mu \mathrm{g} / \mathrm{m} 3$. The flow rate is maintained by volumetric flow controller which is governed by microprocessor. It also averages and stores the ambient temperature, ambient pressure, volumetric flow rate and coefficient of variation of flow rate for the entire sample run time. The procedure of sampling is same as PM10.

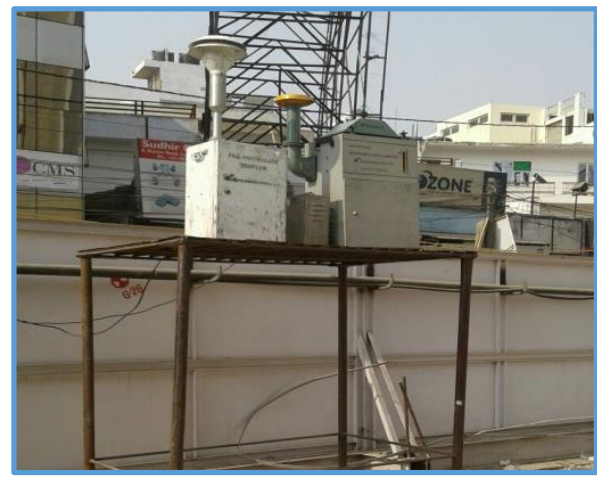

Figure 1: Ambient PM 10 \& PM 2.5 sampler

\subsection{Monitoring of Air Quality:}

The ambient air quality (PM10, PM2.5 etc) were monitored from March 2017 to February 2018 month for Lucknow
Metro Underground single station location. The results were analysed with baseline and NAAQ limits. Seasonal variation on the data have also been observed. Sampling stations were taken based on the factors like predominant wind direction, sensitive receptors, reserve location, topography etc. The frequency of monitoring for ambient air quality was on 24 hourly basis twice in a month. The highest PM10 concentration was recorded at $462.8 \mu \mathrm{g} / \mathrm{m} 3$ while PM 2.5 was found to $275 \mu \mathrm{g} / \mathrm{m} 3$ which were not within the norms of NAAQS and CPCB.

\begin{tabular}{|c|c|c|c|c|c|c|}
\hline Particulars & $\begin{array}{c}\mathbf{1 7 -} \\
\text { Mar }\end{array}$ & $\begin{array}{c}\mathbf{1 7 -} \\
\text { Apr }\end{array}$ & $\begin{array}{c}\mathbf{1 7 -} \\
\text { May }\end{array}$ & $\begin{array}{c}\text { 17- } \\
\text { Jun }\end{array}$ & $\begin{array}{c}\mathbf{1 7 -} \\
\text { Jul }\end{array}$ & $\begin{array}{c}17- \\
\text { Aug }\end{array}$ \\
\hline $\begin{array}{c}\text { PM10 } \\
(\boldsymbol{\mu g} / \mathbf{m} 3)\end{array}$ & 252.2 & 285.5 & 264.4 & 252.6 & 197 & 253.3 \\
\hline $\begin{array}{c}\mathbf{P M 2 . 5} \\
((\boldsymbol{\mu g} / \mathbf{m} 3))\end{array}$ & 163.3 & 175.65 & 161.05 & 172.6 & 110 & 172.8 \\
\hline & $\mathbf{1 7 -}$ & & $\begin{array}{c}\mathbf{1 7 -} \\
\text { Nov }\end{array}$ & $\begin{array}{c}\mathbf{1 7 -} \\
\text { Dec }\end{array}$ & $\begin{array}{c}\mathbf{1 8 -} \\
\text { Jan }\end{array}$ & $\begin{array}{c}\mathbf{1 8 -} \\
\text { Feb }\end{array}$ \\
\hline Particulars & Sep & $\mathbf{1 7 - O c t}$ & & & & \\
\hline $\begin{array}{c}\text { PM10 } \\
(\boldsymbol{\mu g} / \mathbf{m} 3)\end{array}$ & 250.5 & 252.2 & 462.8 & 396.5 & 334.6 & 292.8 \\
\hline $\begin{array}{c}\text { PM2.5 } \\
((\boldsymbol{\mu g} / \mathbf{m} 3))\end{array}$ & 172.1 & 180.3 & 275 & 218.05 & 172.5 & 141 \\
\hline
\end{tabular}

Table No. 1 - PM10 \& PM 2.5 Monitoring data

\section{4: Measurement of Noise:}

Noise measurements have been completed by specific sound level meter during day time. Ambient Noise Analysis was conducted at the same location where ambient air were analysed. LAeq is known as the equivalent level of noise. It expresses the level of irregularly changing noise. It expresses the energy content of variable noise which was in effect at a given time using a value for the level of steady noise which would contain the same quantity of acoustic energy for the same period as the measured noise. The equivalent level of noise is always related to a certain time interval, marked LAeqT.

\begin{tabular}{|c|r|r|r|r|r|r|}
\hline Lday & \multicolumn{1}{|c|}{$\begin{array}{c}\text { 17- } \\
\text { Mar }\end{array}$} & 17-Apr & \multicolumn{1}{|c|}{ 17-May } & $\begin{array}{r}\text { 17- } \\
\text { Jun }\end{array}$ & 17-Jul & 17-Aug \\
\hline LAeq & 62.17 & 65.17 & 63.6 & 65.3 & 62.78 & 60.23 \\
\hline Lday & $\begin{array}{r}\text { 17- } \\
\text { Sep }\end{array}$ & $\mathbf{1 7 - O c t}$ & $\mathbf{1 7 - N o v}$ & $\begin{array}{r}\mathbf{1 7 -} \\
\text { Dec }\end{array}$ & 18-Jan & 18-Feb \\
\hline LAeq & 67.23 & 65.13 & 64.17 & 65.4 & 63.07 & 61.55 \\
\hline
\end{tabular}

Table No. 2 - Noise LAeq Monitoring data

\section{RESULTS AND DISCUSSIONS}

This study is to review and analyze of monitoring data with the baseline survey value to make us understand that construction sector has much impact on the environment although, Lucknow, UP like india's other metropolitan cities ambient Air value was exceeding the NAAQ limits. The added value to the air quality by Lucknow Metro construction has an huge impact on public health although Noise was not much major impact since the project area was on the commercial area where background noise was on higher side. Ambient Air quality baseline was conducted on October 2017 Month. While comparing with baseline value, we have found the monitored results higher than the baseline value. Ambient noise day time found quite satisfactory compared with baseline value. 


\section{RECOMMENDATIONS \& SCOPE OF STUDY}

Generation of dust from construction activities is main cause of PM10 and PM2.5 particle. To mitigate air pollution at sites, the sources of construction dust are identified which includes demolition activities, earthwork, on-site storage of materials, on-site manufacture, transportation, and on-site stacking of waste. The adopted measures for the particulate and gaseous mitigation activities in this project are depicted as follows.

- Demolition activity is carried out by mechanical hydraulic equipment. Continuous water spraying during the demolition prevents dust emission to the atmosphere. Green refine mesh safety net was used. Designated places were particularly arranged for stacking demolition waste and are cleaned periodically. In addition, a workman is assigned for water sprinkling the stacked demolition waste several times a day.

- Earthwork - Dust control measure while earthwork is taken at sites. Continuous water sprinkling is done. Again soil loaded on the vehicle for the disposal are compulsorily compacted and covered with tarpaulins to avoid scattering during transportation.

- Storage of materials for concrete production and road restoration work: Materials are stored in the designated place and again tarpaulins covering and water sprinkling on the materials implementedon regular intervals.

- Transportation - Management of vehicle arrival at sites and departure from the sites also recorded. Wheel wash facility to clean dirts attached on the wheels is provided at entry exit gates of each work sites.

- In the concrete production unit, inside and outside roads are paved to prevent the dust flying to the atmosphere.

Noise emitted in this construction site is within the legal limits for the workers and in the case of the environmental noise there is no specific regulations for these activities.

Noise is controlled at site in the following methods:

- All the plant and equipment used on the site are properly maintained in good operating condition and are provided effectively sound-reduced by means of silencers, mufflers, acoustic linings or shields, acoustic sheds or screens or other means, to avoid disturbance to any nearby noise sensitive receivers.

- All the noise hazard areas (noise level exceeding 75 $\mathrm{dB}$ ) are provided with warning signs.

- All the noise hazard works are strictly adhered to the time restrictions.

- All the personnel's working in the noise hazard areas are provided with personal hearing protectors.

\section{REFERENCES}

[1] Jian Zuo a, d, 2017, Dust pollution control on construction sites: Awareness and self-responsibility of managers, Journal of Cleaner Production 166 (2017) 312-320.

[2] Mahdi Khosravi, 2015 Management and planning under complexities of metro construction, Procedia Economics and Finance 21 (2015) $415-421$.

[3] Curwell, S.R., March, C., Venables, R., 1990. Buildings and Health: the Rosehaugh Guide to the Design, Construction, Use and Management of Buildings. RIBA Publications, London.

[4] ChinaLabourBulletin, 2009. China's Pneumoconiosis Victims Take Drastic Steps in Their Search for Compensation http://www.clb.org.hk/en/content/chinaspneumoconiosis- victimstake-drastic-steps-their-search-compensation (accessed 18.11.13.).

[5] Liang, Y.X., Wong, O., Fu, H., Hu, T.X., Xue, S.Z., 2003. The economic burden of pneumoconiosis in China. Occup. Environ. Med. 60 (6), 383e384

[6] Ulvestad, B., Lund, M.B., Bakke, B., Thomassen, Y., Ellingsen, D.G., 2015. Short-term lung function decline in tunnel construction workers. Occup. Environ. Med. 72, 108- 113.

[7] Toren, K., Jarvholm, B., 2014. Effect of occupational exposure to vapors, gases, dusts, and fumes on COPD mortality risk among Swedish construction workers: a longitudinal cohort study. Chest 145 (5), 992 - 997.

[8] Chauhan, S.K., Sharma, S., Shukla, A., Gangopadhyay, S., 2010. Recent trends of the emission characteristics from the road construction industry. Environ. Sci. Pollution. Res. 17, 1493 1501

[9] Marcos D.Fernández, Noise exposure of workers of the construction sector, Applied Acoustics, Volume 70, Issue 5, May 2009, Pages 753-760.

[10] Ma Jesu's Ballesteros, Noise emission evolution on construction sites, measurement for controlling and assessing its impact on the people and on the environment, Building and Environment 45 (2010) 711-717.

[11] http://cpcb.nic.in/upload/NewItems/NewItem_228_Final_C\&D_ March_2017.pdf.

[12] National Ambient Air Quality Standards (NAAQS) (http://www.cpcb.nic.in)

[13] Radka Kantováa, ${ }^{*}$ Construction Machines as a Source of Construction noise, Procedia Engineering 190 (2017) 92 - 99.

[14] The Noise Pollution (Regulation and Control) Rules, 2000

[15] Zezhou Wu, Mitigating construction dust pollution: state of the art and the way Forward, Journal of Cleaner Production 112 (2016) $1658-1666$

[16] Vichit-Vadakan, N., Ostro, B. D., Chestnut, L. G., Mills, D. M., Aekplakorn, W., Wangwongwatana, S. \& Panich, N. (2001). Air Pollution and Respiratory Symptoms: Results from Three Panel Studies in Bangkok, Thailand, Environmental Health Perspectives, 109(3), pp. 381-387.

[17] Brauer, M., Hoek, G., Smith, H. A., de Jongste, J. C., Gerritsen, J. \& Postma, D. S. (2007). Air Pollution and Development of Asthma, Allergy and Infections in a Birth Cohort, European Society for Clinical Respiratory Physiology, 29(5), pp. 879-888.

[18] European Public Health Alliance, (2009). Air, Water Pollution and Health Effects Retrieved from http://www.epha.org/r/54

[19] Brown MT, Bardi E. Handbook of energy evaluation. A compendium of data for energy computation issued in a series of folios. Folio \#3: Energy of ecosystems. Center for Environmental Policy, Environmental Engineering Sciences, University of Florida, Gainesville; 2001

[20] Gagnesh Jain, Vaishant Gupta, Mukesh Pandey, International Journal of Emerging Technologies in Engineering Research (IJETER) Volume 4, Issue 6, June (2016), Case Study of Construction Pollution Impact on Environment. 